\title{
La concienciación ambiental en el aula de infantil mediante el cine y los cuentos
}

\author{
Ángela Muro González \\ Departamento de Didácticas Específicas (Didáctica de las Ciencias Experimentales) de \\ la Facultad de Formación de Profesorado y Educación de la Universidad Autónoma de \\ Madrid, España. angela.muro.g@gmail.com \\ ORCID: https://orcid.org/0000-0002-8420-219X \\ José Manuel Pérez-Martín \\ Departamento de Didácticas Específicas (Didáctica de las Ciencias Experimentales) de \\ la Facultad de Formación de Profesorado y Educación de la Universidad Autónoma de \\ Madrid, España. josemanuel.perez@uam.es \\ ORCID: https://orcid.org/0000-0002-0658-9050
}

[Recibido: 18 octubre 2020. Revisado: 19 enero 2021. Aceptado: 1 marzo 2021]

Resumen: No podemos ignorar los cambios que está sufriendo el planeta a consecuencia de los actos del ser humano sobre este. Sin embargo, el mayor problema al que nos enfrentamos es la falta de concienciación en la sociedad sobre el cuidado del medio ambiente. Esto conlleva a una necesidad de formación del alumnado en Educación Ambiental (EA) que facilite el conocimiento de las consecuencias que tienen nuestros actos. Por eso, este artículo plantea una propuesta de intervención educativa dirigida a las primeras etapas, en este caso, Educación Infantil (EI), mediante la cual se detectan ideas alternativas, se fomenta la alfabetización de ciudadanos sensibilizados con el medio ambiente y se da respuesta a una petición de propuestas de aula como estrategia de formación continua para maestros. Para lograr todo esto, se proponen recursos didácticos como las películas y los cuentos.

Palabras clave: Educación Ambiental; Educación Infantil; Recursos Didácticos; Alfabetización Científica.

Environmental awareness in the early childhood education's classroom through films and stories

Abstract: Changes that the planet is undergoing as a result of human actions on it cannot be ignored. However, the biggest problem to be faced is the lack of awareness in society about caring for the environment. This leads to a need for training students in Environmental Education (EA) that facilitates knowledge of the consequences of our actions. For this reason, this article raises a proposal for an educational intervention aimed at the early stages, in this case, Early Childhood Education (EI), through which misconceptions are detected, the literacy of citizens is promoted for environmental protection, and a response is given to a request for classroom proposals as a continuous training strategy for teachers. To achieve all this, didactic resources such as films and stories are proposed.

Keywords: Environmental Education; Kindergarten, Didactic Resources; Scientific Literacy.

Para citar este artículo: Muro González, A. y Pérez-Martín, J. M. (2021) La concienciación ambiental en el aula de infantil mediante el cine y los cuentos. Revista de Educación Ambiental y Sostenibilidad 3(1), 1302. doi: 10.25267/Rev_educ_ambient_sostenibilidad.2021.v3.i1.1302

\section{Introducción}

Desde hace años, nos encontramos ante una crisis ambiental derivada del estilo de vida humano que tiene un modelo de interacción sociedad-ambiente insostenible. Los 
problemas medioambientales más relevantes a los que nos enfrentamos son: la sobreexplotación de recursos y la contaminación que juntos derivan en el cambio climático (Bautista-Cerro, Murga-Menoyo y Novo, 2019; Vilches y Gil, 2015).

El principal problema al que nos enfrentamos es la avaricia del ser humano por los recursos que la naturaleza nos presta y la falta de concienciación sobre el cuidado del entorno natural, causando daños intensos al medio y a las especies que en él habitan, incluidos nosotros mismos (Vilches y Gil, 2015). Además, al no tener todo esto unas consecuencias inmediatas o visibles en el momento de realizarse, gran parte de la sociedad no es consciente de sus efectos para el medioambiente, por lo que la EA debe preparar a los ciudadanos para entender las consecuencias de sus actos (MurgaMenoyo y Novo, 2017) a lo largo del tiempo y del espacio.

Conociendo el problema, es importante realizar un cambio en la sociedad. Para ello, es necesario inculcar una serie de valores y una nueva forma de organización en la relación entre los seres humanos y el entorno que les rodea. Para ello, desde hace décadas, diferentes organismos realizan reuniones y conferencias (Bautista-Cerro et al., 2019) para promover cambios en la mentalidad de la sociedad y, por tanto, en su forma de actuar, valorando los problemas medioambientales presentes y proponiendo ciertas soluciones. Lo que se inició en 1975 con la Carta de Belgrado (UNESCO, 1975) ha llegado hasta nuestros días con la Agenda 2030 y los Objetivos de Desarrollo Sostenible (ONU, 2015).

En este contexto, la educación desde etapas tempranas es fundamental y por ello, el presente trabajo expone y analiza los resultados de una propuesta de intervención educativa para trabajar la EA en el segundo ciclo de EI, ya que esta es una de las etapas fundamentales para la formación de la personalidad. Así esta etapa es clave para inculcar en los niños y niñas ${ }^{1}$ la importancia del cuidado del medio ambiente, evitando la contaminación y la sobreexplotación de recursos, y concienciar sobre las consecuencias que nuestros actos tienen sobre este.

\section{Marco teórico}

Desde los años sesenta, el cuidado del medio ambiente ha ido calando en las reformas de la educación obligatoria producidas en los países de nuestro entorno, que han ido recogiendo diversos objetivos sobre la protección del medio ambiente y la sostenibilidad, hasta llegar actualmente a los Objetivos de Desarrollo Sostenible (Benayas y Marcén, 2019).

En aquella época se entendía el ambiente como el medio natural, por lo que únicamente se educaba para su cuidado, pero en los años ochenta se incorporó el medio social, lo que condujo a educar para la concienciación de la crisis ambiental. Y no fue hasta los años noventa cuando se comenzó a considerar la relación entre la economía, los problemas sociales y el ambiente como posible inductora de la crisis ambiental. Actualmente, se ha asentado la idea de una EA no para el medio, sino para el cambio de la sociedad a través de una educación que ayude a los ciudadanos a interpretar, comprender y conocer la complejidad de los problemas existentes, consiguiendo así que estos adquieran unas actitudes, conocimientos, valores, comportamientos, etc., que fomenten ese Desarrollo Sostenible necesario (Bonil, Junyent y Pujol, 2010).

\footnotetext{
${ }^{1} \mathrm{~A}$ partir de aquí, se usará el masculino como genérico (recomendación RAE).
} 
Esta preocupación por el deterioro del medio ambiente trajo un nuevo movimiento de renovación pedagógica, en el que se enseñaba desde lo natural, pretendiendo generar respeto por el medio. En este sentido, Sierra (2012) señala el surgir de dos conceptos: Educación para el Desarrollo Sostenible (EDS) y EA.

La ONU (1987) define el concepto de Desarrollo Sostenible como "la satisfacción de las necesidades de la generación presente sin comprometer la capacidad de las generaciones futuras para satisfacer sus propias necesidades". Además, Novo (2009) señala que la EDS debe mostrarnos los cambios que debemos realizar en nuestros valores, forma de gestión, criterios económicos, ecológicos y sociales, para que podamos satisfacer nuestras necesidades sin que las generaciones futuras se vean afectadas negativamente y así, disminuir el cambio global. Por otro lado, la EA tiene como objetivo fomentar la toma de decisiones para desarrollar habilidades necesarias para mantener una relación beneficiosa entre el hombre y su entorno a través de la propia experiencia (UNESCO, 1990). Por lo tanto, podemos decir que son conceptos superpuestos y no podemos fomentar la EA sin tener presente la EDS y viceversa (Sauvé, 1999). Asimismo, Sierra (2012) indica que no hay acuerdo sobre qué término es más adecuado utilizar, por tener concepciones muy parecidas $\mathrm{y}$, por tanto, cada autor valorará qué término se adecúa más a su propuesta. En este trabajo, utilizaremos el término Educación Ambiental, ya que fundamentalmente pretendemos conseguir una concienciación en los niños sobre la importancia del respeto y cuidado del medio ambiente a través de experiencias en el aula. Además, gracias a su conocimiento, su competencia, sus actitudes, se considera que la población estará en condiciones de contribuir, a la resolución de los problemas actuales y a evitar otros en el futuro (Alonso, 2010).

Los dos factores principales causantes de estos impactos sobre el medio ambiente son: la necesidad de la población por consumir cada vez más recursos para sobrevivir (sobreexplotación), y la emisión de residuos, que producen graves daños en la salud ambiental y humana (Álvarez, 2007; Vilches y Gil, 2015).

En este sentido, a la hora de promover el cuidado del medio ambiente desde las aulas, nos encontramos con carencias formativas en EA de los docentes (Aznar, Ull, Martínez y Piñero, 2014; Cantó, 2016; Pérez-Martín et al., 2019). Además de formación, los docentes siempre solicitan, de la investigación educativa, propuestas de aula para ser aplicadas (Murillo y Perines, 2017) y también en el ámbito científico debido al poco reconocimiento académico de estas publicaciones (Esquivel-Martín et al., 2019).

Vilches y Gil (2012) destacan la importancia de que los estudiantes que terminan estudios universitarios hayan adquirido competencias básicas en sostenibilidad. Cantó (2016), en el caso de los maestros en formación, mostró que los futuros maestros presentan conocimientos incompletos y sesgados sobre el Desarrollo Sostenible y los actores que deben implicarse en la búsqueda de soluciones, por lo que deben superar concepciones reduccionistas. Aunque también debería priorizarse la capacitación en el juicio crítico y en la creación de propuestas de intervención educativa, lo que no está muy extendido (Reigosa y Pérez-Martín, 2019).

En esta línea, Aznar et al. (2014) sugieren la necesidad de activar planes de formación continua para el profesorado en relación con la sostenibilidad. Además, señalan que cualquier propuesta de formación universitaria para el desarrollo de competencias básicas en cuanto al Desarrollo Sostenible debe integrar tres tipos de contenidos: 
cognitivos (saber), procedimentales (saber hacer) y actitudinales (saber ser y valorar), adquiriendo el profesorado, de esta manera, una comprensión crítica de la problemática social, económica y ambiental. Por tanto, con estos contenidos podrán aplicar propuestas didácticas que promuevan la toma de decisiones y acciones coherentes con la sostenibilidad, desarrollando el sentido de la responsabilidad en las propias acciones y decisiones.

También se destaca la necesidad de que los ciudadanos estén capacitados para la toma de decisiones en cuanto a las relaciones con el medio ambiente y la actuación del ser humano en él. Por ello, es imprescindible trabajar en las aulas la alfabetización científica y la toma de decisiones (Pérez-Martín y Bravo-Torija, 2018; Pérez-Martín et al., 2019). Además, estos autores resaltan que los programas formativos de corte ambiental se limitan en presentar problemas globales y soluciones convencionales, como las 3R (Reciclaje, Reducción y Reutilizar); y en sus trabajos proponen actividades educativas sobre problemas próximos, promoviendo que las soluciones propuestas por los estudiantes sean los cambios para revertir la situación tratada. Esto se debe a que, como mencionan, en los programas formativos las soluciones sugeridas no suponen cambios en las conductas de los alumnos, dado que las situaciones presentadas son lejanas y les hace poco participes en la toma de decisiones. Estos autores consideran importante el paso que deben dar los alumnos entre la distribución de conocimientos y la participación en la toma de decisiones, siendo posible el paso por la capacitación en destrezas científicas como pueden ser la búsqueda de información, el cuestionamiento de lo aprendido y el desarrollo del pensamiento crítico.

Este déficit de formación que existe en el profesorado sobre la EA, junto con la escasez de programas, actuaciones e investigaciones relacionadas con la EA en EI (Rojano y Jiménez, 2017), demandan realizar investigaciones educativas y propuestas de trabajo en aulas sobre este tema.

Los sistemas educativos nórdicos se adaptan para lograr una educación para la sostenibilidad siguiendo en la etapa preescolar la regla de las 7Rs: reducir, reutilizar, reciclar, respetar, reflexionar, reparar y responsabilidad (Rojano y Jiménez, 2017). En esta línea hay que destacar la propuesta de Reigosa y Pérez-Martín (2019) que se centra en EI, y presenta un catálogo de acciones que promueven conductas cotidianas sostenibles que se categorizan siguiendo las $7 \mathrm{R}$, como el reciclaje de papel, la reutilización de materiales biodegradables para fabricar comederos para pájaros, la revalorización de productos de desecho para fabricar juguetes o la reflexión sobre las conductas cotidianas, entre otros.

Sin embargo, podemos resaltar que, en las etapas de Educación Infantil y Primaria, las experiencias llevadas al aula en España se mueven generalmente en el marco de la presentación de problemas de contaminación ambiental del suelo y del agua. Una de estas experiencias es el proyecto de innovación educativa propuesto por García y Guzmán (2010), que consiste en una ecoauditoría, cuyo objetivo es conocer el impacto ambiental de los residuos generados dentro del aula y del entorno familiar con el fin de reducirlos y fomentar el cuidado y mejora del medio ambiente.

En esta línea, se realizan actividades centradas en la sobreexplotación de recursos naturales, donde se centra en mencionar el concepto y no es llevado a la práctica dentro del aula como es el caso de Guardeño (2016). Sin embargo, la experiencia 
realizada por Pérez-Rojo (2013) muestra acciones para evitar la sobreexplotación de recursos, como la plantación de tilos, reutilización de recursos como el papel y usa recursos audiovisuales para presentar las consecuencias de la sobreexplotación.

Por otro lado, los recursos empleados en las diferentes experiencias, cabe destacar las películas (García y Guzmán, 2010; Pérez-Rojo, 2013) para llevar a cabo su ecoauditoría y la presentación de realidades contextualizadas que las recrean y dan verosimilitud (García, 2007) y fomenta actitudes positivas y adecuadas para el aprendizaje de las ciencias (Grilli, 2016). Asimismo, uno de los recursos más extendidos en las aulas de EI son los cuentos (Espinet, 1995), ya que son la forma narrativa más antigua que se conoce y es, además, considerado un universal cultural que permite dar sentido al mundo y a la experiencia humana, y al igual que el cine contextualiza. Sin embargo, García-Castejón (2013) señala la escasez de cuentos científicos infantiles en España. En este sentido, la propuesta por Pérez-Martín y Bravo-Torija (2018) trata la extinción de especies en EI empleando cuentos que presentan la deforestación. El trabajo es a través de preguntas mediadoras, con ellas dirigimos la reflexión de los niños hacia donde consideremos importante, haciendo que relacionen mejor los conceptos (García-González y Pérez-Martín, 2016). En muchas ocasiones, en estos trabajos se recurre al dibujo como método de análisis del conocimiento de los niños, ya que son un recurso analítico muy potente (Goodnow, 1979), sobre todo en aquellas etapas donde los alumnos tienen un escaso dominio de la escritura, y suele acompañarse con una descripción oral de lo que han plasmado en el papel, evitando realizar análisis erróneos (Marín, 1988).

Por todo lo dicho hasta aquí, los docentes necesitan una formación inicial y continua más adecuadas a sus necesidades. Una forma interesante de hacerlo es a través de propuestas de aula publicadas en revistas de investigación educativa, en la que se presenten estas intervenciones, lo que convertiría a la investigación educativa en una herramienta de innovación real para el autoaprendizaje en el ejercicio profesional docente (Esquivel-Martín, Bravo-Torija y Pérez-Martín, 2019).

En este sentido, nuestra propuesta de intervención educativa pretende cubrir estas necesidades, ya que promueve que los docentes en ejercicio mejoren su formación a nivel conceptual, procedimental y actitudinal; propone un conjunto de actividades y recursos de interés para las aulas de EI; y, además, en ella se despliega una herramienta útil para la detección de ideas previas en EI, lo que ha sido poco trabajado hasta ahora (Cantó, Pro y Solbes, 2016). Como recogen diferentes autores (Malleus et al., 2017; Moreno, 2017), la recopilación de ideas previas está en la base del constructivismo, todos los aprendices tienen conocimientos previos sobre cualquier tema adquiridos en sus experiencias cotidianas y, a partir de ellos, se construyen los nuevos aprendizajes. Por tanto, detectar aquellas que los dificultan es clave para mejorar las propuestas de aula. En este sentido, diferentes autores han puesto de manifiesto la necesidad de explorar las ideas alternativas que aparecen en la enseñanza de problemas ambientales, fundamentalmente en el ámbito universitario y de la Educación Secundaria y, en menor medida, de Educación Primaria (Ver Moreno, 2017). Sin embargo, se mantienen casi inexploradas en EI, ya que son mucho más escasos los estudios publicados en esta etapa (Cantó et al., 2016; Siry y Kremer, 2011). Su detección ayudaría en gran medida a la elaboración de propuestas de aula eficaces en el ámbito de la EA que permitan superar estas ideas previas. 


\section{Objetivos}

Ante esta situación, los objetivos de este trabajo son dos:

- Analizar y detectar las ideas previas sobre contaminación y reciclaje en niños de EI.

- Proponer actividades y recursos útiles para trabajar la EA y para la Sostenibilidad, empleando recursos educativos como cuentos y películas que fomenten la concienciación sobre la sobreexplotación de recursos naturales y la contaminación.

\section{Metodología}

\section{Participantes}

Las experiencias se realizaron con 25 alumnos (13 niñas y 12 niños) de 4 años de EI de un centro escolar público en Madrid. La intervención fue guiada por la docente e investigadora, que además participó activamente en el diseño de la propuesta didáctica. Las actividades se desarrollaron en el segundo y tercer trimestre del curso, y conocían desde el inicio del curso, la separación de residuos en el marco del reciclaje como acción de protección medioambiental. Asimismo, no habían trabajado el ciclo del agua previamente.

\section{Recursos didácticos}

Los recursos empleados en esta propuesta didáctica son cuentos y películas. En este caso, el cuento utilizado fue de elaboración propia (http://t.ly/rJhI), donde se trabaja la contaminación por residuos y las consecuencias que éstos tienen en el medio. Las películas de animación infantil utilizadas presentan problemáticas medioambientales:

- Rango: Hace referencia a la sobreexplotación de los recursos naturales (agua).

- Lórax: Hace referencia a la sobreexplotación de recursos naturales (deforestación).

- Happy feet: Hace referencia a la contaminación marina (animal atrapado en las anillas de plástico de las latas).

\section{Propuesta de intervención}

A partir de las actividades que se presentan (Anexo: Tabla suplementaria 1), valoramos qué saben los niños de EI sobre la contaminación ambiental, qué conceptos de EA interiorizan e incorporan entre sus hábitos. La estrategia didáctica consistió siempre en unas preguntas iniciales, el desarrollo de una actividad, unas preguntas finales y un dibujo sobre el tema abordado después de la intervención. Todo ello con el fin de que se produjese una reflexión profunda de sus saberes y conductas.

\section{Secuenciación de actividades}

A) Primera etapa: Conocimientos previos

Se realiza un cuestionario oral en grupos de 5 niños, para detectar los conocimientos previos de los niños sobre los problemas ambientales, las preguntas fueron:

- ¿Sabes qué es la contaminación?

- ¿Qué pasa si no cerramos el grifo mientras nos lavamos los dientes? 
- ¿Qué es el reciclaje? ¿Quién lo hace en casa? ¿Cómo?

- ¿Qué pasa si tiramos basura al suelo?

- ¿Debemos ir más andando o en coche?

- ¿Alguien sabe cómo debemos cuidar el medio ambiente (calle, parques, campo, playas, etc.)?

- ¿Quién ha ido a la playa y ha visto basura en ella, es decir, latas, papel, plásticos, etc.?

- ¿Qué puede pasar si tiramos basura al mar?

Una vez se ha realizado el cuestionario en pequeños grupos de 5 alumnos, se pusieron las ideas en común en asamblea, donde se grabó el debate para transcribirlo y categorizar las respuestas obtenidas.

B) Segunda etapa: Descripción de los conocimientos previos.

Individualmente, los niños en pequeños grupos de 5 alumnos realizaron un dibujo sobre los problemas ambientales tratados el día anterior en la asamblea. Posteriormente, les preguntamos uno a uno qué es lo que habían plasmado de los problemas ambientales, y los analizamos.

C) Tercera etapa: Concepto de contaminación.

En esta sesión, se introdujo en asamblea el concepto de contaminación. Para valorar sus conocimientos previos e introducir cambios conceptuales, nos apoyamos en imágenes de entornos contaminados y limpios (Figura 1) y demandamos que identificasen cada uno de ellos. Al finalizar la asamblea, se pidió que realizasen un dibujo con la temática: ¿Qué es la contaminación?, que permitió comparar los resultados del debate previo con los dibujos.
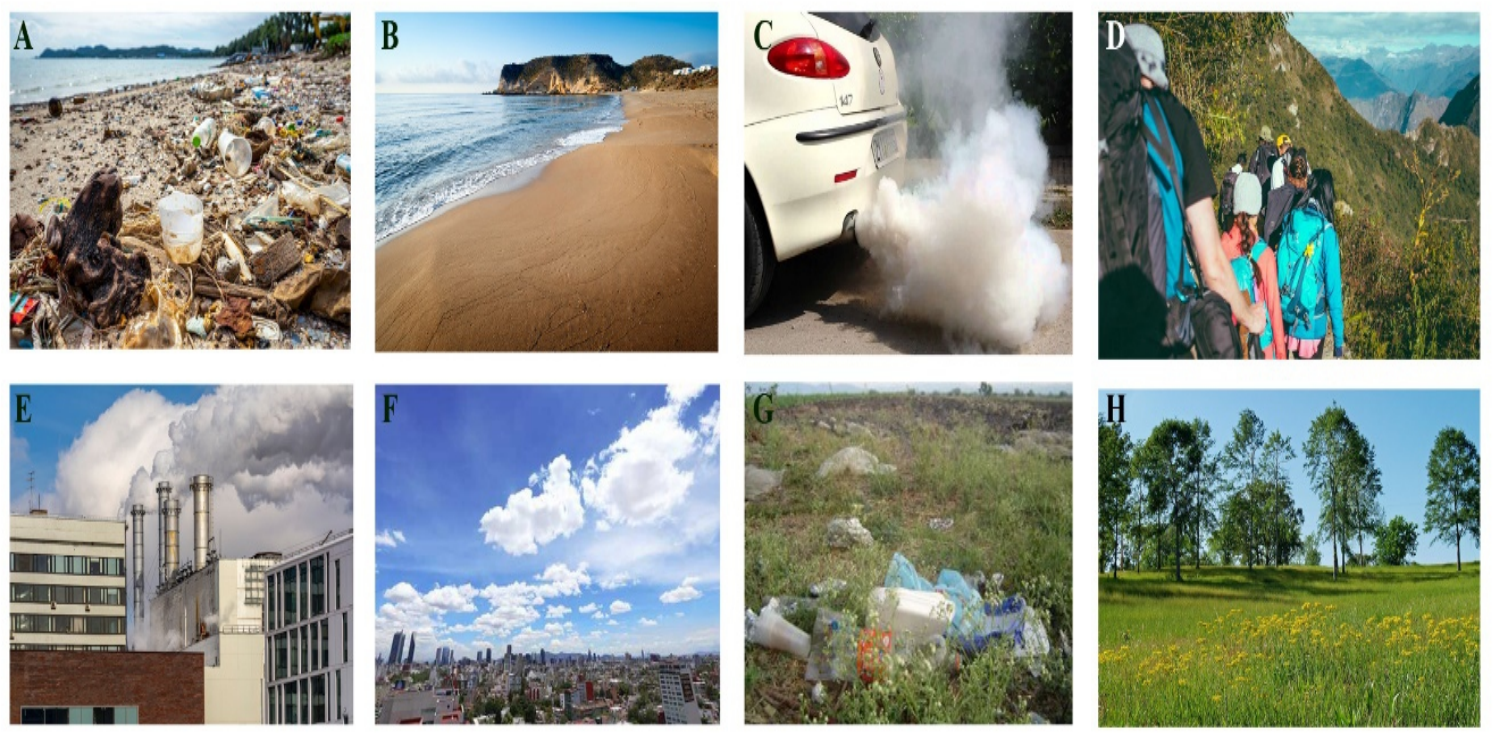

Figura 1. Imágenes utilizadas en la actividad. Playa contaminada por basura (A), playa limpia (B), coche contaminando el aire por la expulsión de gases (C), actividad física que no afecta al medio (D), fábricas contaminando el aire por expulsión de gases (E), cielo sin contaminación (F), campo con basura (G) y campo sin basura (H). Fuente: Elaboración propia. A: http://t.ly/XVnh; B: http://t.ly/ugzd; C: http://t.ly/R5XE; D: http://t.ly/YfqY; E: http://t.ly/KqR4; F: http://t.ly/QHdY; G: http://t.ly/k4gc; H: http://t.ly/6Gul. 
D) Cuarta etapa: ¿Puede pasarle a nuestro planeta?

En esta fase, se proyectaron fragmentos de películas infantiles (Figura 2) en los que se presentaba alguna problemática ambiental. Tras verlas, en grupo, conversamos sobre imágenes fijas de las películas (¿Cómo creían que había podido pasar?, etc.). Finalmente preguntamos si creían que lo que veían en las imágenes podía pasar en la realidad, y tras responder, mostramos esos problemas con imágenes reales, abriendo de nuevo un debate sobre cómo podríamos evitar dichos problemas y qué consecuencias tienen.
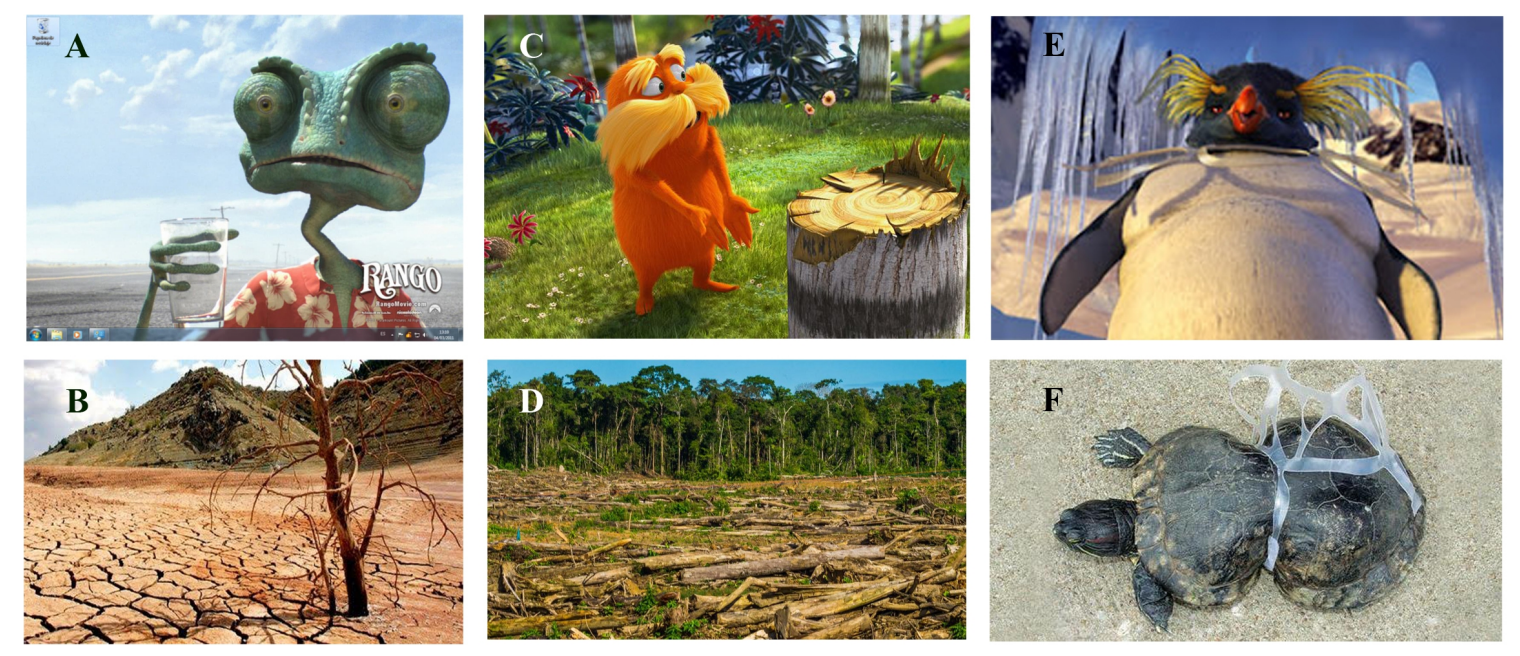

Figura 2. Escena de Rango (A) y consecuencias de la sequía (B). Escena de Lórax (C) y tala de un bosque (D). Escena de Happy Feet (E) y consecuencia de la contaminación marina (F). Fuente: Elaboración propia. A: http://t.ly/wkSi; B: http://t.ly/2Jwb; C: http://t.ly/3v0c; D: http://t.ly/nGKR; E: http://t.ly/WykY; F: http://t.ly/ZCbH.

E) Quinta etapa: Contaminación marina.

Para conocer mejor los conocimientos previos de los niños acerca de los animales marinos, se les preguntó:

- ¿Cómo son los animales marinos?

- ¿Dónde viven?

- ¿Qué animales marinos conocéis?

- ¿Alguien sabe qué es esto? (Mediante imágenes impresas, se les mostraron anémonas, corales, erizos de mar, estrellas de mar y peces)

- ¿Qué animal marino os gusta más? ¿Por qué?

Posteriormente, se realizaron varias preguntas mediadoras, para iniciar la aproximación al cuento. Las preguntas que realizamos fueron las siguientes:

- ¿Quién es este personaje? (Señalando la portada del cuento)

- ¿Sabéis dónde vive?

- ¿Qué creéis que va a pasar en el cuento?

Tras estas conversaciones, se procedió a la lectura del cuento de elaboración propia (http://t.ly/rJhI) en asamblea. Durante la lectura, se lanzaron las siguientes preguntas mediadoras: 
- ¿Quién creéis que es el animal extraño?

- ¿Qué puede estar haciendo?

Al terminar el cuento, se hizo una puesta en común sobre lo que pensaban acerca de los problemas abordados en el cuento, mediante las siguientes preguntas:

- ¿Creéis que lo que estaba haciendo Lucas está bien?

- ¿Qué os parece la solución?

- ¿Cómo creéis que han llegado al mar esos plásticos, latas, bolsas?

Finalizadas todas estas preguntas, les pedimos que realizasen un dibujo del arrecife de coral del cuento. En el caso de que dibujasen un arrecife de coral en mal estado les pedimos que propusiesen una solución para remediarlo.

\section{Análisis de los resultados}

La recogida de datos se realizó en pequeños grupos de 5 alumnos. Las respuestas se registraron en una grabación de audio, se transcribieron y se categorizaron para realizar los gráficos de respuestas (primera etapa). En el caso de los dibujos (segunda etapa), se categorizaron en función de los conceptos que presentaban:

- Consecuencias de la contaminación

- Posibles soluciones a los problemas medioambientales

- Las 3Rs (reducir, reutilizar y reciclar)

En la tercera etapa los conceptos que se pretendían encontrar en los dibujos se debían reducir a las consecuencias de la contaminación (falta de agua, suciedad, etc.) y posibles problemas medioambientales (contaminación por residuos, sequía, etc.), ya que en esta etapa se explicitó el concepto de contaminación. Para realizar el análisis de los dibujos se preguntó a los niños qué es lo que habían dibujado y se transcribió en el mismo dibujo. Finalmente, se realizó un análisis de contenido de las respuestas del alumnado (Bardin, 1996) y el sistema de categorías ha sido construido en interacción con los datos, posteriormente se cuantificaron las respuestas y para la realización de las gráficas se empleó Microsoft Excel (Microsoft ${ }^{\circledR}$ Excel $^{\circledR}$ 2016, EE.UU.).

\section{Resultados}

\section{Pre-intervención: Conocimientos previos sobre la contaminación}

En esta primera fase, se comenzó con una serie de preguntas para analizar qué saben los niños sobre la contaminación (Figura 3). Como se pude observar en la figura 3A, se muestran las respuestas a la pregunta: “¿Qué es la contaminación?”, y tras obtener la respuesta de los 25 alumnos, podemos señalar sólo 4 lo asocian con ensuciar ("El planeta está sucio"), y esta sería la categoría que muestra mayor nivel de desempeño. El resto de respuestas muestran niveles menores. Por ejemplo, "no tirar basura" (5 casos) se mueve en la línea de que no hay que ensuciar el planeta y, además, tener soluciones ante esto, pero no permiten conocer si saben qué es la contaminación, aunque tienen cierta relación con los residuos. El resto, asocian la contaminación con problemas de sostenibilidad y cuidado del medio ambiente, mencionando la sobreexplotación de los recursos ("si no tenemos agua, nos secamos") y la salud humana y ambiental ("tenemos algo en el cuerpo que nos pone malitos"). Y por último hay algunas respuestas que nada tienen que ver ("el planeta explota"), que graficamos 
como respuestas erróneas. Entendemos que la expresión oral es una destreza que requiere de más tiempo de maduración en esta etapa, y aunque hay algunas respuestas que podríamos decir que se aproximan a la respuesta de referencia, la que esperaríamos que manejasen podría ser cercana a que los desechos que generamos diariamente se liberan al medio ambiente desordenadamente y ocupan espacios del entorno natural que no que corresponden. Por lo tanto, la que más se acerca es la idea de que "el planeta está sucio".

La contaminación tiene su origen en los desechos que generamos y su presencia en el entorno. A partir de ahí, se les preguntó si sabían qué es "reciclar". A pesar de tener en el aula los cubos para reciclar, 20 de los participantes no supieron responder a esta pregunta, mientras que 4 de ellos relacionaron el reciclaje con la limpieza como podemos ver en la figura 3B. Con todo ello, llama la atención este desconocimiento, que quizás tiene su origen en la publicidad sobre el reciclaje, que suele estar únicamente asociada con la separación y en ocasiones solo se presenta así en las aulas.

A

¿Qué es la contaminación?

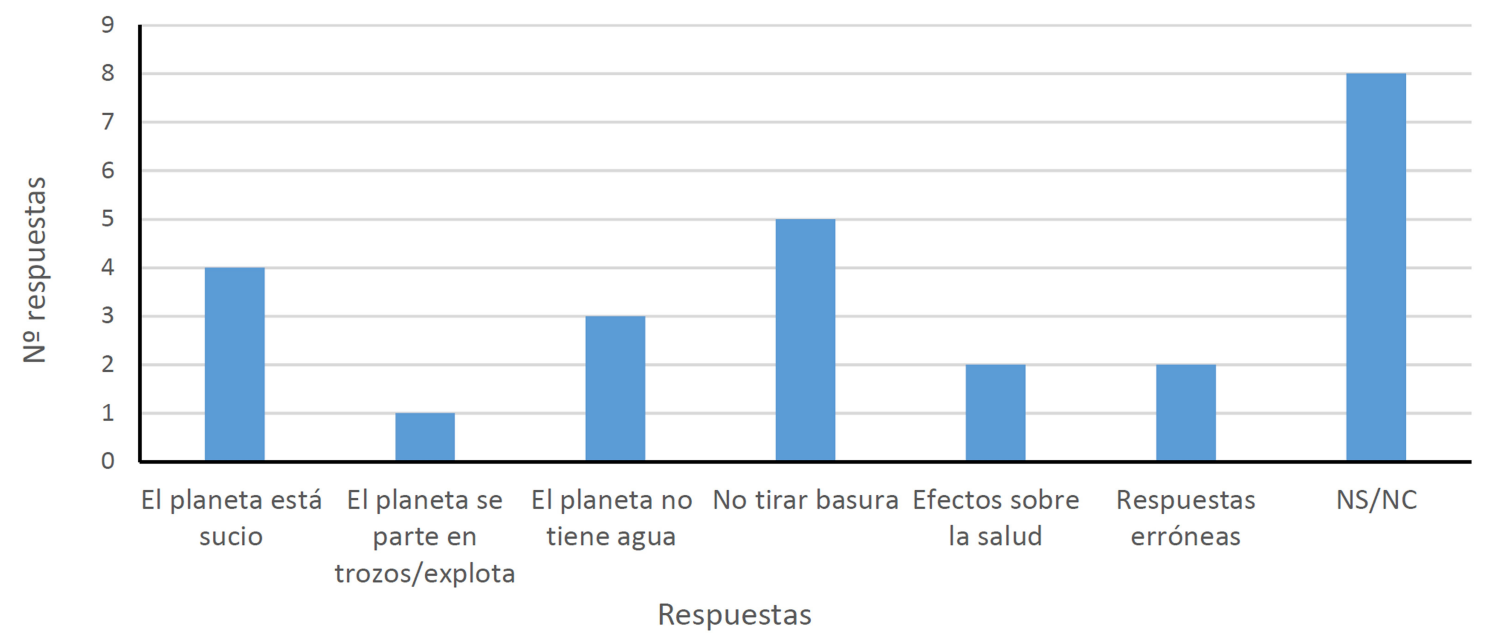

B

¿Qué es el reciclaje?

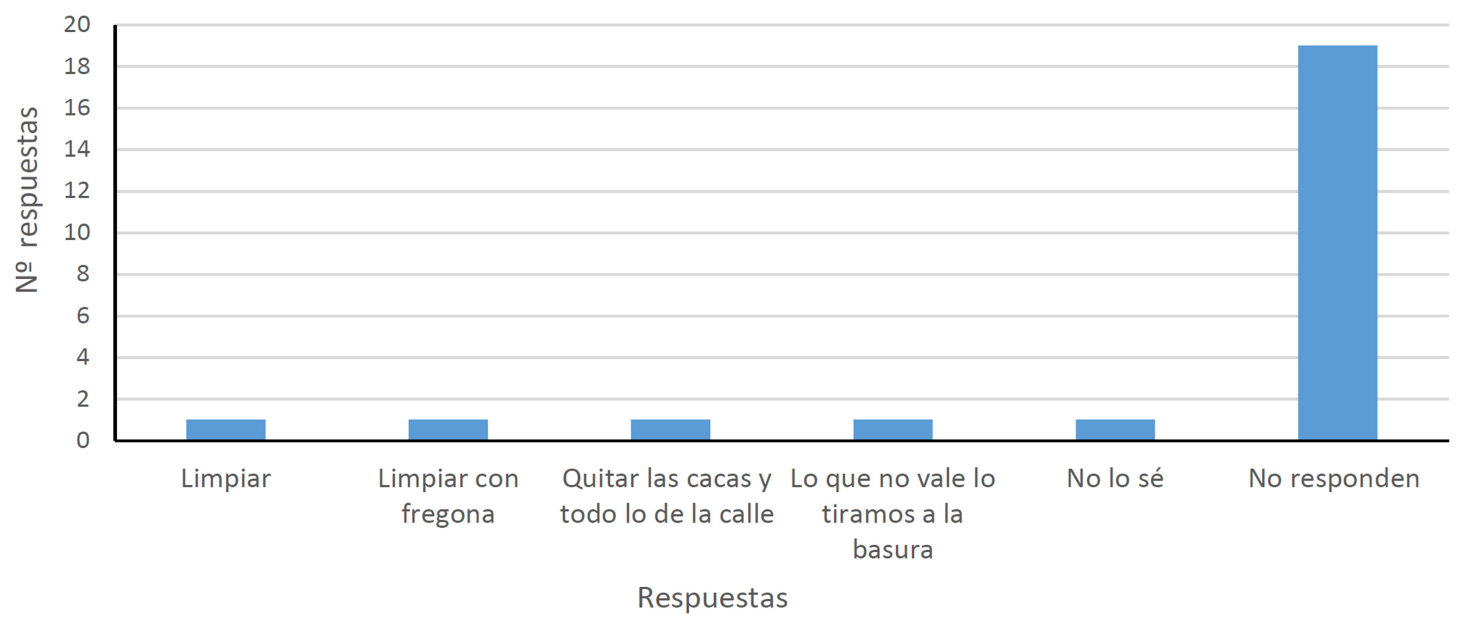

Figura 3. Conocimientos previos de los alumnos. Respuestas de los niños ante la pregunta ¿qué es la contaminación? (A). Respuesta ante la pregunta ¿qué es el reciclaje? (B). En ambos casos no hubo explicación previa. Fuente: Elaboración propia. 
En la figura 4, se muestran las ideas que tienen los niños acerca de las consecuencias que tienen nuestros actos sobre el medio, en este caso las preguntas están enfocadas hacia el agotamiento de recursos como el agua (Figura 4A), donde se muestra que la mayoría de los niños (13) no responden a: “QQué pasa si no cerramos los grifos?”. Diez más consiguen relacionarlo con la falta de agua y con la ausencia de hidratación, es decir, si no tenemos agua no podemos beber ni nosotros ni los animales. Tres de ellos, indican que al dejar el grifo abierto perdemos agua del mar, embalses o playas, lo que supone una idea alternativa relacionada con el ciclo del agua. En cuanto a la pregunta sobre las consecuencias de tirar basura al suelo (Figura 4B), se vuelve a mostrar el desconocimiento general y destacamos que sólo un participante relacionó tirar la basura al suelo con el daño a seres vivos (plantas).

A

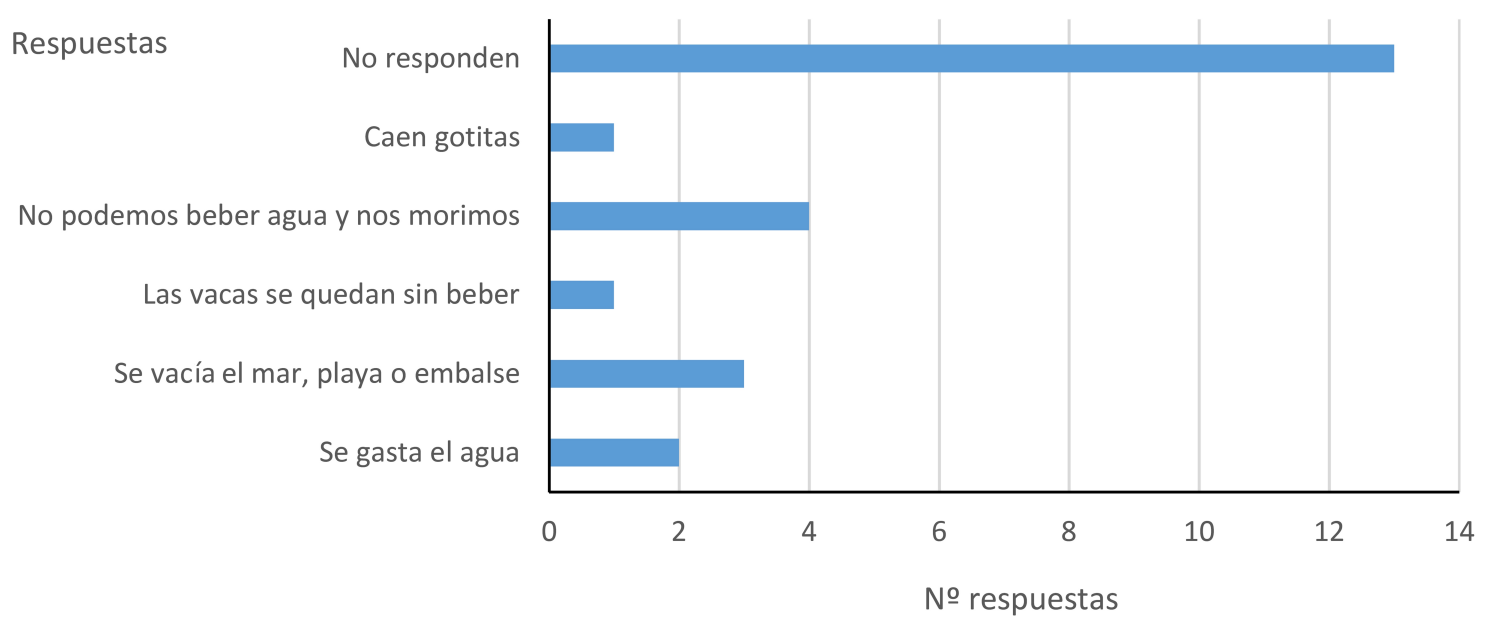

$\mathrm{B}$

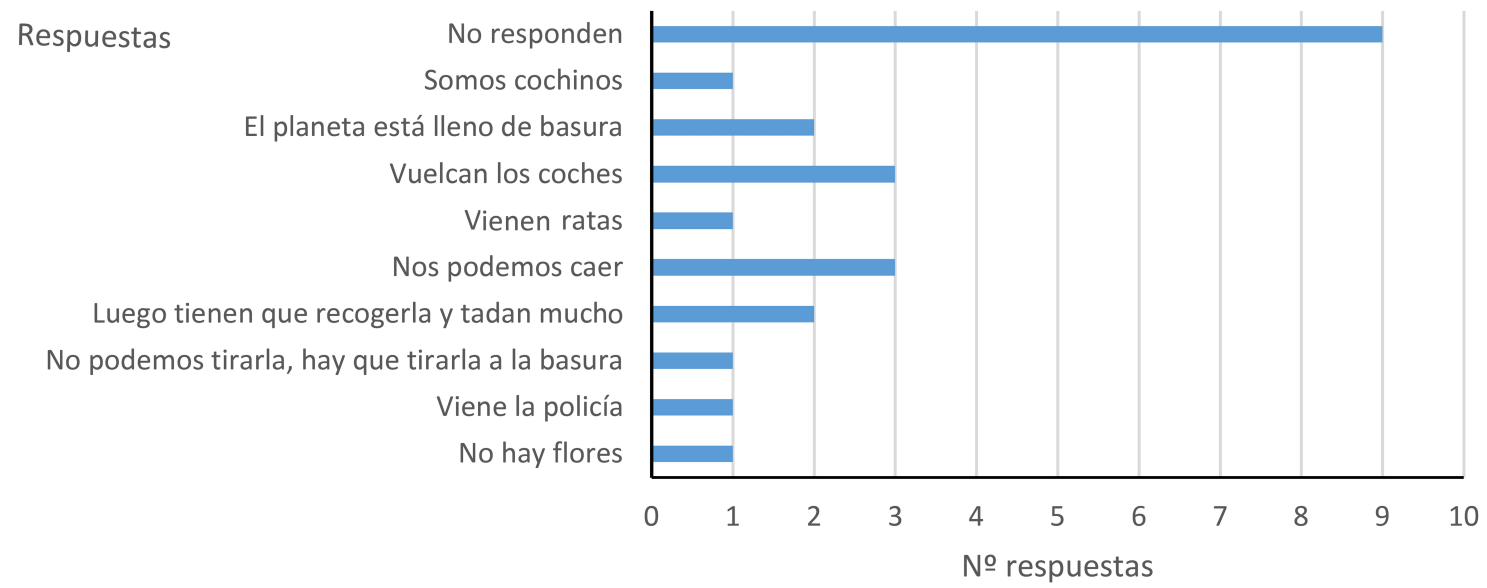

Figura 4. Consecuencias de los actos humano por dejar los grifos abiertos (A) y por tirar basura al suelo (B). Fuente: Elaboración propia.

En la figura 5, se muestra la percepción sobre el uso de coches para el medio ambiente. Más del $50 \%$ de los niños (Figura 5A) respondieron que "es mejor ir en coche ya que caminando te cansas y tardas más"; por el contrario, un porcentaje menor señaló que "es mejor ir andando porque en coche rompemos todo y nos 
hacemos daño por culpa del humo que echan". Sin embargo, las ideas que tienen sobre la contaminación producida por los coches no están claras (Figura 5B), mencionando la gasolina y el fuego, o no sabiendo responder. Solo 4 de 25 niños supieron responder correctamente a: “¿Qué echan los coches por detrás?”.

Al preguntar sobre los daños causados por los coches sobre la salud y el medio ambiente, partimos de la respuesta: "los coches echan humo". En este caso, también 4 participantes responden correctamente "el humo se queda en las personas y en la calle” (Figura 5C). Es cierto que esta pregunta, “¿Dónde se queda el humo?”, puede resultar ambigua, ya que 6 respuestas mencionan que "el humo de los coches se queda detrás". Posiblemente debido a que la pregunta anterior lo sugiere. En la figura $5 \mathrm{D}$, podemos ver que la mayoría (21 de 25 ) no sabe o no contesta, y que sólo 4 son parcialmente correctas, que serían: "nos tragamos el humo", porque el humo se queda en el aire que respiramos y esto provoca que esté sucio, y puede impedir que respiremos correctamente ("no podemos respirar"), lo que, si el aire que respiramos está contaminado, puede afectar a nuestra salud, y esto podríamos asociarlo a la respuesta "nos morimos".

A

¿Es mejor ir andando o en coche?

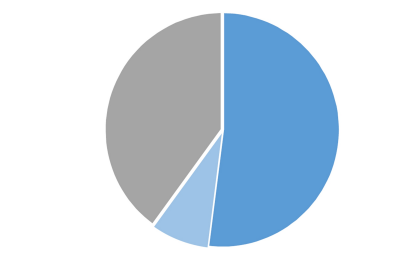

- Coche, para no cansarnos

$\square$ Andando, en coche hacemos daño por el humo

- No responden

$\mathrm{C}$

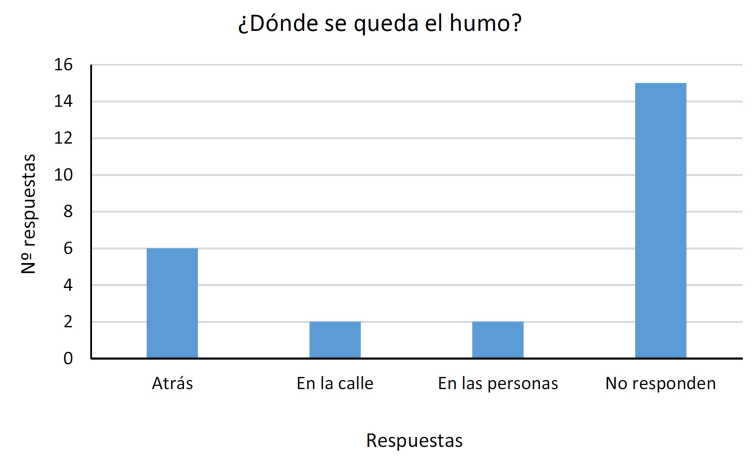

B ¿Qué echan los coches por detrás?

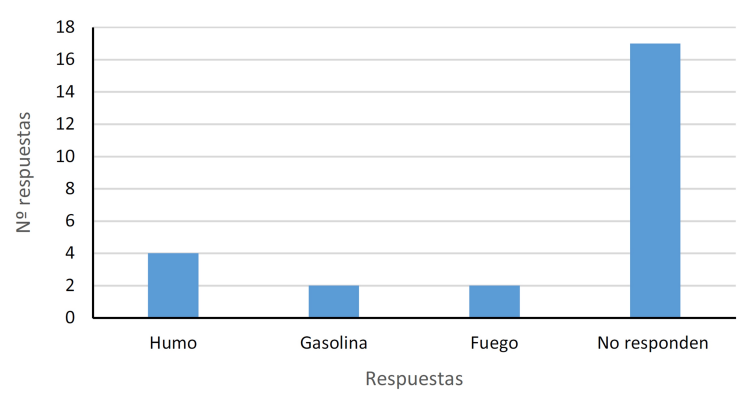

D

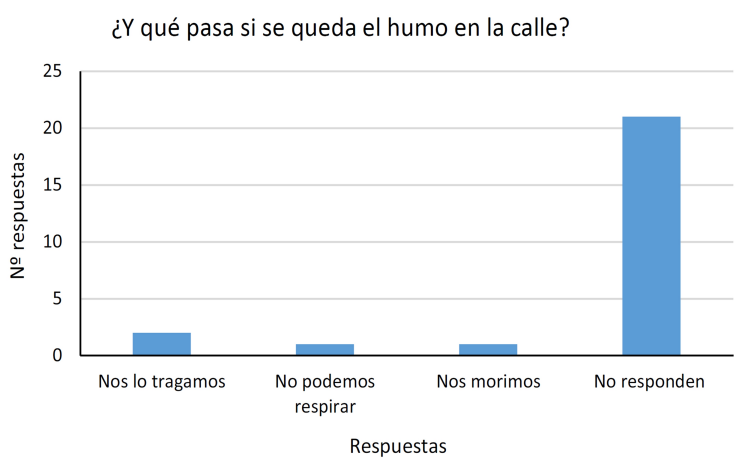

Figura 5. Ideas sobre las consecuencias del uso de los coches, sobre ir caminando a los sitios (A), sobre el humo de los coches (B, C y D). Fuente: Elaboración propia.

Analizando las causas de la contaminación, les preguntamos si habían ido a la playa y en el caso afirmativo, si habían visto basura. Solo cinco respondieron afirmativamente, y cuatro describieron la basura que vieron: cigarrillos, bolsas, latas, cáscaras de fruta y cristales. Posteriormente, quisimos analizar la percepción de los niños sobre la consecuencia de tirar la basura a la playa, y la mayoría de las respuestas (Figura 6) están relacionadas con el daño de la vida tanta humana como animal ("se mueren los animales" o "los animales se ponen malos"). 


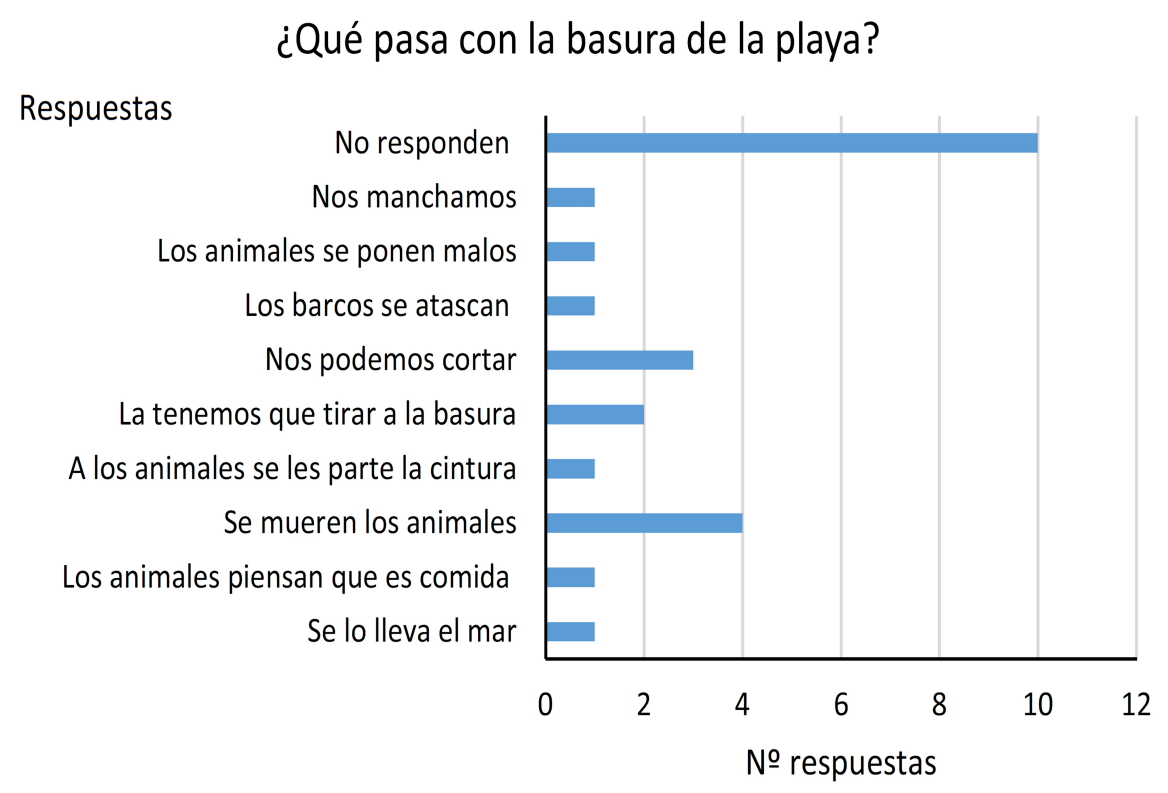

Figura 6. Consecuencias de tirar la basura a la playa. Fuente: Elaboración propia.

\section{Post-intervención sobre la contaminación: después del debate}

Al finalizar las sesiones de intervención, se volvió a preguntar: “¿Qué es la contaminación?" (Figura 7). En este caso, 4 de los participantes indican que la contaminación significa que "el planeta está sucio", que sería lo más próximo a lo correcto. Sin embargo, otras respuestas ("el planeta no tiene agua" o "que nos afecta a la salud") son consecuencias de estar contaminado. El incremento de "no responden" aumentó en la post-intervención, probablemente debido a la dificultad de definir la contaminación con palabras, una vez entendido qué es.

¿Qué es la contaminación?

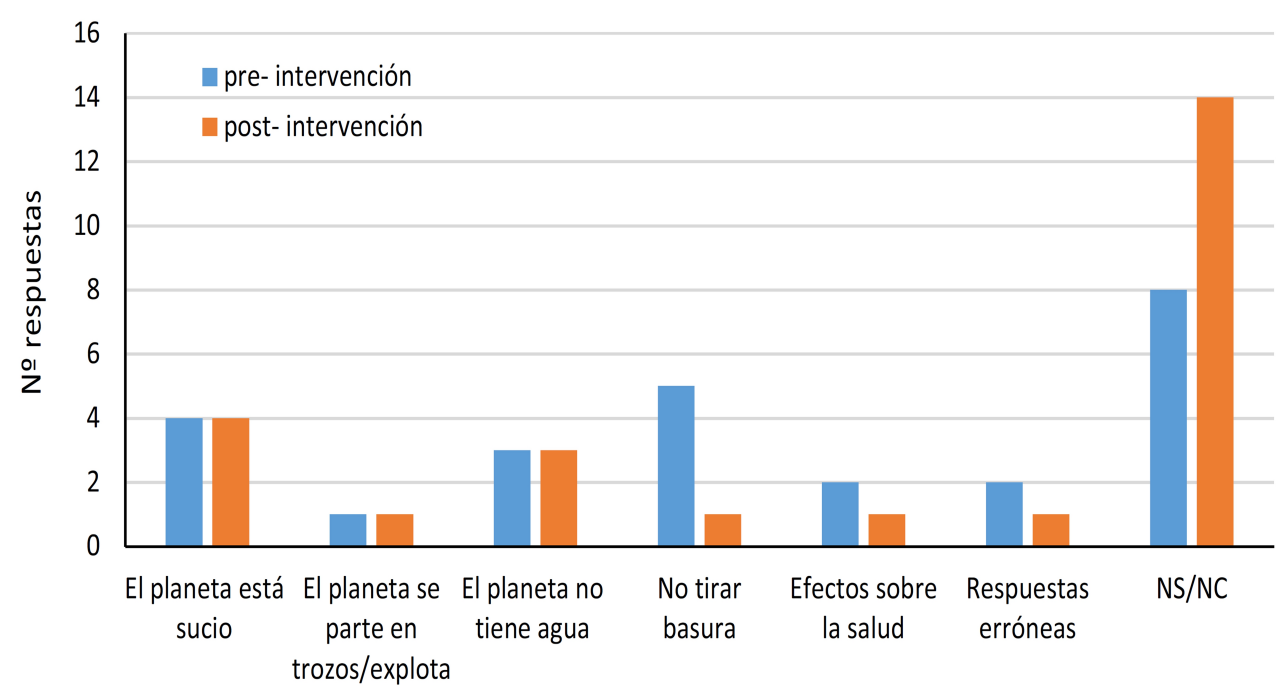

Respuestas

Figura 7. Comparación de las ideas de los niños sobre el concepto de contaminación antes y después de la intervención. Fuente: Elaboración propia 
Sin embargo, cuando analizamos las ideas de los niños sobre la contaminación a través de los dibujos, se pude ver una clara mejora al finalizar las actividades (Figura $8 \mathrm{~A}$ ), ya que las ideas están más claras. La mayoría de los niños representó en sus dibujos factores que provocan contaminación (humo de los coches o el mar lleno de basura), lo que nos permitió inferir la esencia que muchos de ellos verbalizaban posteriormente: "la contaminación es cuando el planeta está sucio". Además, se mencionan ambientes contaminados, la contaminación atmosférica y la acuática; aunque, alguno señala la ausencia de agua (sobreexplotación de recursos), en lugar de contaminación.

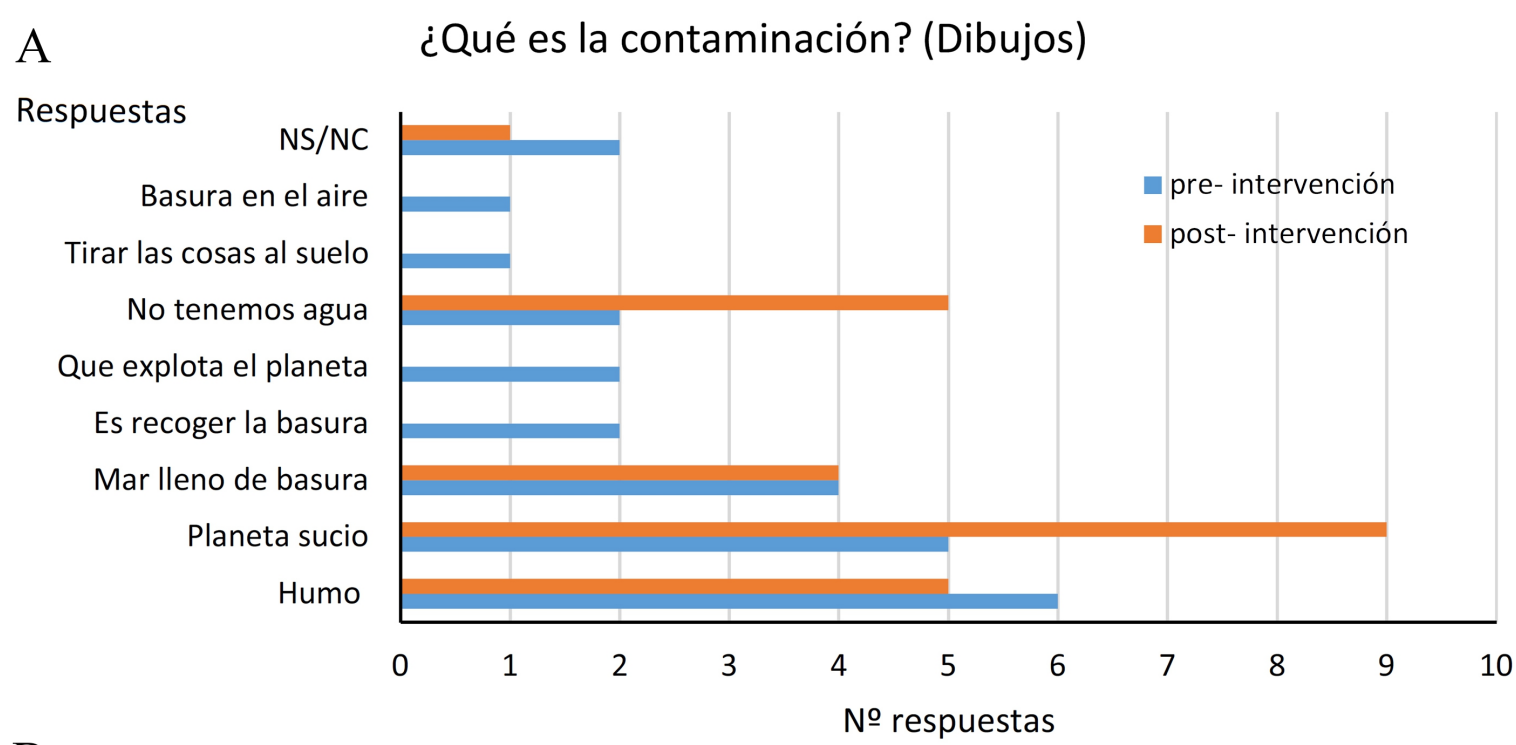

B

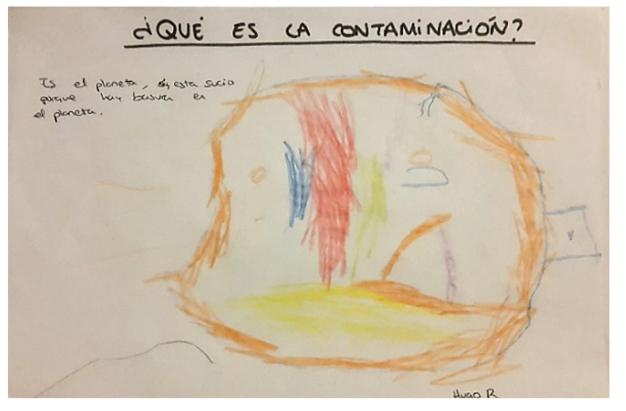

"Es el planeta, está sucio porque hay basura en el planeta".

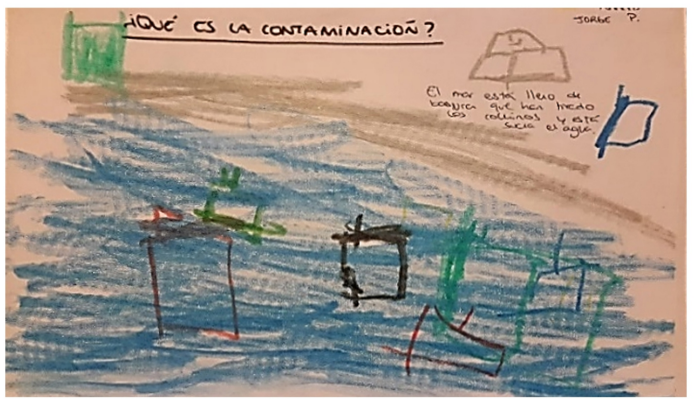

"El mar está lleno de basura que han tirado los cochinos y está sucia el agua".

Figura 8. Análisis de contenido de los dibujos realizados por los niños sobre la contaminación antes y después de la intervención (A). Dibujos representativos recogidos tras la actividad con la explicación del autor (B). Fuente: Elaboración propia.

\section{Actividad sobre las consecuencias de la contaminación y la sobreexplotación de recursos}

En la cuarta etapa se les mostraron imágenes sobre diferentes problemas ambientales presentes en películas infantiles (Figura 2). El objetivo de esta actividad era llevar a los niños a la reflexión de si estas escenas de las películas podían suceder en su entorno próximo. Al mostrarles las imágenes de las películas, dudaron de si podían ocurrir en su entorno más próximo, pero tras la reflexión individual de lo que ocurría en cada imagen (contaminación y sobreexplotación de recursos naturales), y lo 
relacionaron con situaciones de la vida real (Figura 9). Solo 3 de los alumnos respondieron que esto no era posible, que "solo pasa en las películas", o incluso que "no, porque no quiero que pase". En el caso de las respuestas afirmativas, además asociaron las causas que provocaban dichas situaciones. Por ejemplo, en la escena de la película Rango consiguieron detectar la sequía como consecuencia de malgastar agua; en la película Lórax asociaron la deforestación y la tala de árboles; y en la última película, Happy Feet, fueron capaces de relacionar la contaminación del medio marino causada por residuos sólidos que los humanos tiran tanto al mar como al suelo.

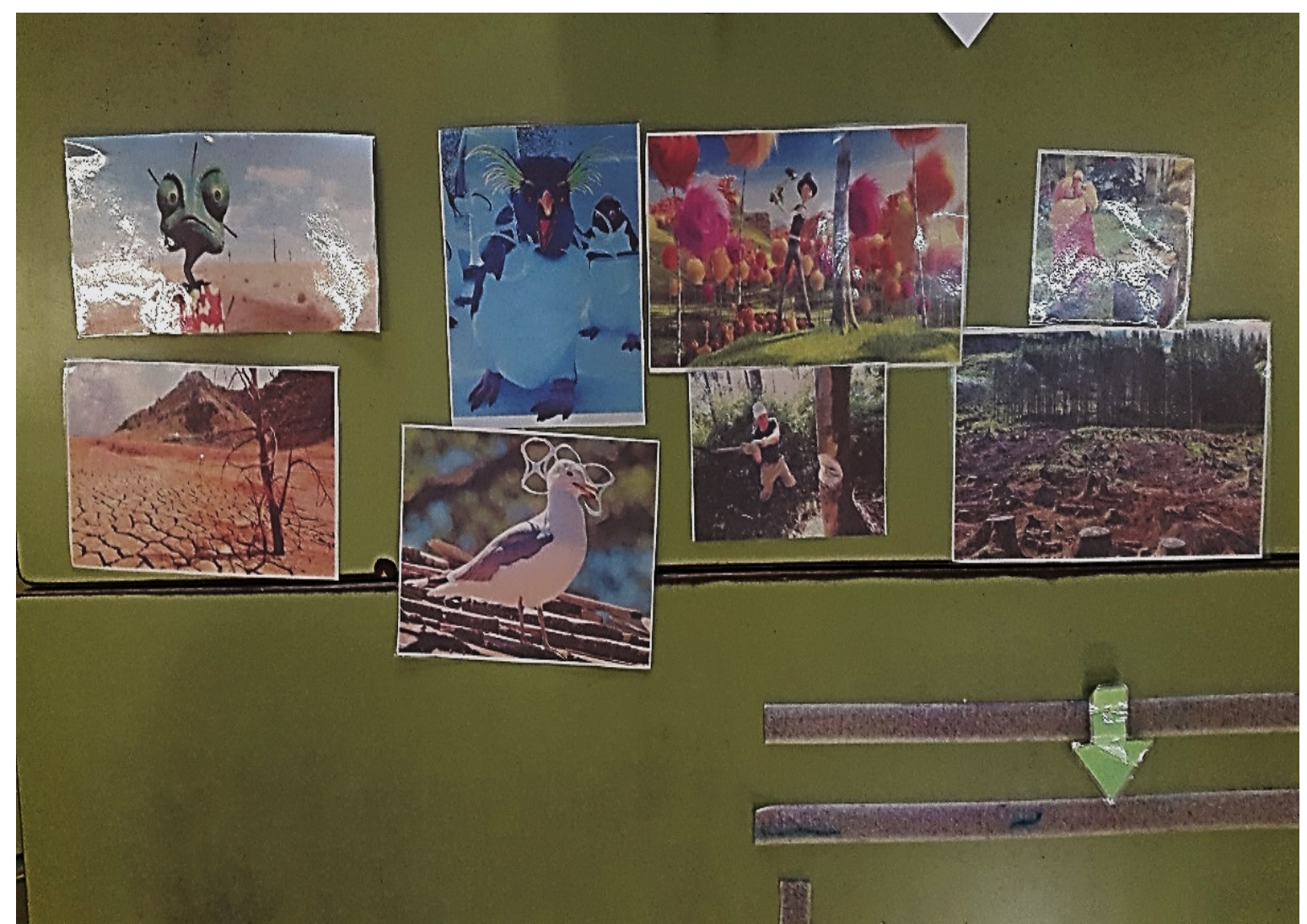

Figura 9. Panel elaborado para relacionar escenas de películas con fotografías reales. Fuente: Elaboración propia.

\section{Actividad sobre las consecuencias de la contaminación marina: lectura de un cuento}

Tras realizar las preguntas mediadoras, pudimos observar que todos los niños cuestionaban las acciones del personaje del cuento (captura de los animales y plantas del arrecife de coral). Por último, se les preguntó: “¿qué quitarían o añadirían al cuento?" La idea más repetida fue: "Quitaría al buzo malo que se está llevando a los peces, y pondría uno bueno que no se los lleve".

En pequeños grupos, pedimos que dibujasen el arrecife de coral del cuento, tal y como lo hubiesen imaginado durante la lectura del cuento (limpio o contaminado). La mitad de la clase dibujó un arrecife de coral limpio, indicando que esto se debía a que nadie tiraba basura ni en el mar ni en la playa (Figura 10A). La otra mitad lo dibujó sucio, lo que nos permitió enfrentarles a la situación de cómo lo limpiarían ellos (Figura 10B). 
A

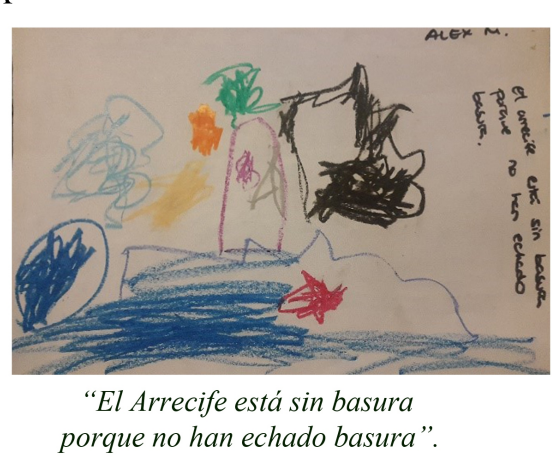

B

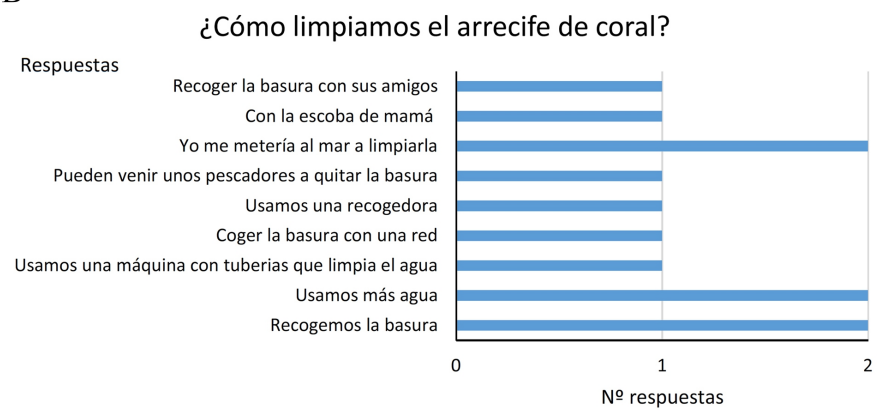

Figura 10. Dibujos sobre los arrecifes. Los niños señalan que están limpios porque nadie tira basura (A). Ideas que dieron los niños sobre como quitar la basura del mar o del arrecife de coral (B). Fuente: Elaboración propia.

Finalmente, en asamblea recopilamos todas las ideas sobre el cuidado del medio ambiente, y los niños destacaron en lo que respecta a la contaminación que "no hay que tirar la basura al suelo" y que usemos "el contenedor correcto". Por otro lado, destacaron la importancia de evitar malgastar recursos como el agua, ya que "es un tesoro y la necesitamos para beber y para las plantas".

\section{Discusión y conclusiones}

En general, las experiencias desarrolladas en aulas de EI (García y Guzmán, 2010; Guardeño, 2016; Pérez-Martín y Bravo-Torija, 2018) se centran en trabajar la contaminación por residuos sólidos para fomentar la concienciación ambiental, aunque se mencionen someramente la sobreexplotación de recursos. Sin embargo, la propuesta presentada aquí, trabaja la contaminación (sólidos y gases) y la sobreexplotación de los recursos naturales (agua y bosques) de manera equilibrada, permitiendo entender las consecuencias que sus actos tienen sobre el medio ambiente. El principal motivo por el que se ha diseñado y desarrollado esta propuesta es el bajo nivel de conocimiento científico de los docentes de EI (Cantó et al., 2016) que les hace tener una concepción reduccionista sobre la sostenibilidad (Cantó, 2016). Por lo que, esta experiencia puede replicarse en distintos contextos para ayudar a la introducción de la ciencia en las aulas de EI, mejorando el nivel de dominio del contenido del docente; y además facilitar la adquisición de competencias básicas sobre sostenibilidad y la concienciación ambiental de sus alumnos, para que les permitan comprender tanto los componentes básicos del medio natural, como el valor de su importancia y la influencia para la vida de los seres humanos en él.

Una vez analizados los resultados, se puede decir que quizás las estrategias de enseñanza sobre EA tienen poco impacto en las primeras etapas educativas, por diferentes motivos ya que, a pesar del hincapié en el problema de la contaminación y la importancia del reciclaje (películas, publicidad, cubos de colores, etc.), la mayoría de los participantes mostraron ideas alternativas sobre estos conceptos, presentando conocimientos imprecisos ("si no tenemos agua, nos secamos") o alejados de la realidad ("La Tierra se parte en trozos" o "el planeta explota"). A pesar de no ser capaces de describir qué es la contaminación, saben que provoca efectos sobre la salud y el entorno natural ("Tenemos algo en el cuerpo que nos pone malitos"). Por lo tanto, saben lo que implican estas situaciones y acciones, pero presentaron dificultades a la hora de expresarlo oralmente. Esta situación también se dio cuando 
se les preguntaba sobre si era posible que se dieran situaciones concretas, y nos dimos cuenta de que el manejo de subjuntivo no estaba bien adquirido, y confundían posibilidad con deseo. Por lo tanto, aquí se manifiesta la dificultad de obtener registros de resultados cuando se trabaja con esta etapa educativa (Cantó et al., 2016). Por lo que, tras analizar la herramienta didáctica, se demuestra la necesidad de trabajar la expresión oral como destreza científica comunicativa (Pro, 2013), y por otro lado ayudar a definir los fenómenos e introducir situaciones vivenciales. De modo que los niños vean las consecuencias que tienen sus actos en su entorno más próximo, lo que posteriormente afectará a entornos más lejanos (Murga-Menoyo y Novo, 2017; Pérez-Martín y Bravo-Torija, 2018).

En este punto, nuestros resultados avalan los resultados previos que muestran al dibujo como una poderosa herramienta en EA (Eugenio-Gozalbo, Aragón y OrtegaCubero, 2020), y que ha permitido analizar los conocimientos adquiridos por los alumnos en una etapa donde las destrezas de comunicación oral y escrita son escasas (Cantó et al., 2016; Goodnow, 1979). En conjunto, las actividades de expresión oral y plástica demuestran que los conocimientos son adquiridos, aunque sus capacidades comunicativas orales sean reducidas, y que su comunicación mejora cuando utilizan dibujos para transmitir sus saberes científicos, mostrando al dibujo como una poderosa herramienta de comunicación científica (Ainsworth, Prain y Tytler, 2011). Por lo tanto, el análisis de la alfabetización científica que promueva concienciación ambiental se puede llevar a cabo desde edades muy tempranas.

Los recursos propuestos en este artículo se centran principalmente en la concienciación, que sería uno de los primeros pasos para lograr una alfabetización científica la cual, como señalan diferentes autores (Herrera y Ríos, 2017; Pérez-Martín y Bravo-Torija, 2018; Sauvé, 2004) nos permitiría formar ciudadanos capacitados para la toma de decisiones en cuanto a las relaciones con el medio ambiente y nuestra actuación sobre él. Además, no descartamos que se promuevan otras capacidades, ya que en algunos casos se dan situaciones donde los alumnos proponen soluciones o asocian problemas ambientales reales con escenas de ficción. Por lo tanto, nuestros resultados sugieren que con el uso de imágenes reales mostrando las consecuencias de nuestros actos sobre el medio ambiente, promovimos la toma conciencia y la propuesta de soluciones. Este resultado puede deberse a que las imágenes realistas facilitan el establecimiento de relaciones conceptuales (Ganea et al., 2014). Sin embargo, una de las limitaciones de nuestra herramienta es que no permite ver la participación de los alumnos en la acción, únicamente nos permite analizar las ideas y no los hábitos de los alumnos. Por lo que, como mencionan Vega y Álvarez (2005, p. 2) "el conocimiento por sí solo no produce cambios automáticos en las conductas", dicho de otra manera, para que la EA sea efectiva, la concienciación debe ir dada de la mano de la vivencialidad o experiencias reales en entornos de acción, si no, podrían quedar limitadas al buenismo ambiental (Pérez-Martín et al., 2019). Por todo ello, sería bueno resaltar la idea de que, en esta etapa educativa, la expresión oral del concepto es posterior a su adquisición, ya que puede aparecer en la expresión plástica o incluso en las acciones y actitudes. Lo que nos exige que en el futuro diseñemos herramientas de análisis y acciones educativas que permitan analizar dichas adquisiciones ajustándonos a las capacidades de los niños de este nivel educativo. 
Por otro lado, como punto a favor, podemos señalar que el cine y los cuentos facilitan la concienciación gracias a que las películas (García, 2007; Grilli, 2016) y los cuentos (García-Castejón, 2013; Huertas, 2006; González, 2006; Mateos, Bejarano, Moreno, 2015; Pérez-Martín y Bravo-Torija, 2018) tienen un gran potencial de atracción y contextualizan los problemas ambientales mostrados. dando verosimilitud y sentido a la situación descrita. A pesar de lo poderoso de estas herramientas, no es sencillo encontrar cuentos científicos rigurosos, y menos aún cuentos ambientales (Cortés y García-Morís, 2014), por lo que el cuento utilizado es de elaboración propia, para ajustarnos mejor a lo que se pretende trabajar.

Por lo tanto, con esta intervención en el aula de EI, en la que se emplean recursos didácticos muy extendidos en la educación (cuentos y películas) hemos conseguido sensibilizar a los niños sobre problemas ambientales como la contaminación y la sobreexplotación de recursos, y promover la propuesta de soluciones por su parte. Además, se han detectado y reconstruido sus ideas previas sobre contaminación y reciclaje de alumnos de EI. Esto demuestra lo interesante y útil de seguir profundizando en el conocimiento sobre el aprendizaje de las ciencias en edades tempranas, para mejorar la Educación Ambiental y el Desarrollo Sostenible. Por último, nos gustaría resaltar el interés por elaborar propuestas de aula y publicarlas en revistas de investigación, que ayuden al profesorado en su práctica diaria, ya que también con esto se ayuda a su formación continua. Y, por otro lado, mejora su percepción de la investigación educativa, ya que la ven alejada de la resolución de sus problemas de aula (Esquivel-Martín et al., 2019), y con este tipo de trabajos, ayudamos a cerrar esa brecha entre práctica educativa e investigadora en la enseñanza de las ciencias.

\section{Agradecimientos}

Este artículo se enmarca en los trabajos de innovación educativa derivados de la Cátedra UNESCO de Educación para la Justicia Social. Asimismo, ha sido financiado por el proyecto titulado "Marine Litter Hub: creación de una comunidad de aprendizaje expandida" - UAM 2107/0243 (programa 128800), dedicado a crear y divulgar prácticas de Educación Ambiental que promuevan la protección del medio marino; y por el proyecto "La democracia en las escuelas como fundamento de una Educación para la Justicia Social" (EDU2017-82688-P).

\section{Referencias bibliográficas}

Ainsworth, S., Prain, V., \& Tytler, R. (2011). Drawing to Learn in Science. Science, 333(6046), 1096-1097. https://doi.org/10.1126/science.1204153

Alonso Marcos, B. (2010). Historia de la Educación Ambiental. La Educación Ambiental en el Siglo XX. Asociación Española de Educación Ambiental. https://aeea.es/wp-content/uploads/2016/06/Historia-de-la-educacion-ambiental.pdf

Álvarez, L. (2007). Conciencia y conducta medioambiental: los paisajes culturales. INTERSTICIOS, Revista Sociológica de Pensamiento Crítico, 1(1). https://www.intersticios.es/article/view/709

Aznar, P., Ull, A., Martínez, M. P., \& Piñero, A. (2014). Competencias básicas para la sostenibilidad, un análisis desde el diálogo disciplinar. Revista de pedagogía, 66(2), 13-28. https://doi.org/10.0.50.242/Bordon.2014.66201

Bardin, L. (1996). El análisis del contenido. (2ª edición). Akal. 
Bautista-Cerro Ruiz, M. J., Murga-Menoyo, M. A., \& Novo, M. (2019). La Educación Ambiental (página en construcción, disculpen las molestias). Revista de Educación Ambiental y Sostenibilidad, 1(1), 1103. https://doi.org/10.25267/Rev_educ_ambient_sostenibilidad.2019.v1.i1.1103

Benayas, J., \& Marcén C. (Eds.) (2019). Hacia una Educación para la Sostenibilidad. 20 años después del Libro Blanco de la Educación Ambiental en España. Informe 2019. Centro Nacional de Educación Ambiental (CENEAM), Ministerio para la Transición Ecológica. https://www.miteco.gob.es/es/ceneam/recursos/materiales/haciaeducacion-sostenibilidad_tcm30-496569.pdf

Bonil, J., Junyent, M., \& Pujol, R. M. (2010). Educación para la Sosteniblidad desde la perspectiva de la complejidad. Revista Eureka de Enseñanza y Divulgación de la Ciencia, 7(Número Extraordinario), 198-215. http://dx.doi.org/10.25267/Rev_Eureka_ensen_divulg_cienc.2010.v7.iextra.05

Cantó Doménech, J. (2016). Percepción de la Sostenibilidad en los maestros en formación de Educación Infantil. Indagatio Didáctica, 8(1). http://hdl.handle.net/10550/58983

Cantó, J., Pro, A., \& Solbes, J., (2016) ¿Qué ciencias se enseñan y cómo se hace en las aulas de Educación Infantil? La visión de los maestros en formación inicial. $\begin{array}{llll}\text { Enseñanza de las } & \text { 25-50. }\end{array}$ http://dx.doi.org/10.5565/rev/ensciencias.1870

Cortés Mármol, C., \& García-Morís, R. (2014). Propuesta metodológica para una Didáctica del Medio Ambiente en Educación Infantil: La investigación sobre cuentos ambientales. En R. Martínez Medina, \& E. M. Tonda Monllor (Coords.), Nuevas perspectivas conceptuales y metodológicas para la educación geográfica, Vol. II, (pp. 139-152). Grupo de Didáctica de la Geografía de la Asociación de Geógrafos Españoles. http://hdl.handle.net/10396/12463

Espinet Blanch, M. (1995). El papel de los cuentos como medio de aprendizaje de las ciencias en la Educación Infantil. Aula de Innovación Educativa, (44), 59-64.

Esquivel-Martín, T., Bravo-Torija, B., \& Pérez-Martín, J. M. (2019). Brecha entre Investigación y Praxis Educativas en la Enseñanza de Biología. REICE. Revista Iberoamericana sobre Calidad, Eficacia y Cambio en Educación, 17(4), 75-91. https://doi.org/10.15366/reice2019.17.4.004

Eugenio-Gozalbo, M., Aragón, L., \& Ortega-Cubero, I. (2020). Gardens as Science Learning Contexts across educational stages: Learning assessment based on students' graphic representations. Frontiers in Psychology, (11), 2226. https://doi.org/10.3389/fpsyg.2020.02226

Ganea, P., Canfield, C. F., Simons-Ghafari, K., \& Chou, T. (2014). Do cavies talk? The effect of anthropomorphic picture books on children's knowledge about $\begin{array}{lllll}\text { animals. Frontiers in Psicology, } & 283 .\end{array}$ https://doi.org/10.3389/fpsyg.2014.00283

García Cárceles, M. V., \& Guzmán Martínez-Valls, D. (2010). Ecoauditoría escolar: los residuos en el aula. Una propuesta para Educación Infantil. II Jornadas de los Máster en Investigación e Innovación en Educación Infantil y Educación 
Primaria.

Universidad

de

Murcia.

https://www.um.es/c/document_library/get_file?uuid=dad63469-6e6b-47a3bb5f-3676b0374544\&groupId=299436

García-González, S., \& Pérez-Martín, J. M. (2016). Enseñanza de las ciencias naturales en educación primaria a través de cuentos y preguntas mediadoras. Revista Internacional de Investigación e Innovación en Didáctica de las Humanidades y las Ciencias, (3), 101-122. http://didacticahumanidadesyciencias.com/ojs/index.php/RIDHyC/article/vi ew/46/pdf

García-Castejón Rodríguez, M. M. (2013). La narrativa en la enseñanza de las ciencias de la naturaleza. Investigación en la escuela, (79), 79-85. https://doi.org/10.12795/IE.2013.i79.07

García, R. (2007). El cine como recurso didáctico. Eikasia. Revista de Filosofía, (13), 121-127. https://www.revistadefilosofia.org/numero13.htm

González López, I. (2006). El valor de los cuentos infantiles como recurso para trabajar la transversalidad en las aulas. Campo abierto, 25(1), 11-29. http://hdl.handle.net/11162/28147

Goodnow, J. (1979). El dibujo infantil. Morata.

Grilli, J. (2016). Cine de ciencia ficción y enseñanza de las ciencias. Dos escuelas paralelas que deben encontrarse en las aulas. Revista Eureka sobre enseñanza y divulgación de las ciencias, 13(1), 137-148. https://revistas.uca.es/index.php/eureka/article/view/2957/2698

Guardeño Maldonado, A. (2016). Proyecto educativo: Nuestros amigos los animales. TFG de Grado Maestros Educación Infantil de la Universidad de Granada. http://hdl.handle.net/10481/45866

Herrera Araya, D., \& Ríos Muñoz, D. (2017). Educación ambiental y cultura evaluativa. Algunas reflexiones para la construcción de eco-consciencias. Estudios Pedagógicos 43(1), https://www.redalyc.org/pdf/1735/173553246022.pdf

389-403.

Huertas Gómez, R. M. (2006). Literatura Infantil: El cuento y su valor educativo. En: E. Miraflores Gómez, \& J. Quintanal Díaz (Edts.), Educación infantil: orientaciones y recursos metodológicos para una enseñanza de calidad, (pp. 353-376). Editorial CCS.

Malleus, E., Kikas, E., \& Marken, T. (2017). Kindergarten and primary school children's everyday, synthetic, and scientific concepts of clouds and rainfall. Research in Science Education, 47(3), 539-558. https://doi.org/10.1007/s11165-0169516-z

Marín Viadel, R. (1988). El dibujo infantil: tendencias y problemas en la investigación sobre la expresión plástica de los escolares. Arte, individuo y sociedad, 5(1), 529. https://revistas.ucm.es/index.php/ARIS/article/view/ARIS8888110005A

Mateos Jiménez, A., Bejarano Franco, M., \& Moreno García, D. (2015). Los cuentos y los juegos de simulación para trabajar la justicia social en el ámbito de las ciencias 
en las primeras edades. Revista Internacional de Educación para la Justicia Social, 3(1), 97-119. https://revistas.uam.es/riejs/article/view/358

Moreno Fernández, O. (2017). ¿Qué sabes de la contaminación? Estudio de las ideas previas en alumnado de Educación Primaria. Revista Electrónica de Enseñanza de las Ciencias, 16(3), 502-515. http://reec.uvigo.es/volumenes/volumen16/REEC_16_3_5_ex963.pdf

Murga-Menoyo, M. A., \& Novo, M. (2017). Sostenibilidad, Desarrollo «Glocal» y Ciudadanía planetaria. Referentes de una Pedagogía para Desarrollo Sostenible. Teoría educativa. Revista interuniversitaria, 29(1), 55-78. https://doi.org/10.14201/teoredu2915579

Murillo, F. J., \& Perines, H. (2017). Cómo los docentes no universitarios perciben la investigación educativa. Revista Complutense de Educación, 28(1), 81-99. https://doi.org/10.5209/rev_RCED.2017.v28.n1.48800

Novo, M. (2009). La educación ambiental, una genuina educación para el desarrollo sostenible. Revista de Educación, (Número Extraordinario), 195-217. http://hdl.handle.net/11162/74555

ONU (1987). Nuestro futuro común. Asamblea General de las Naciones Unidas. A/42/PV.42 de 20 de octubre de 1987. https://undocs.org/pdf? symbol=es/A/42/PV.42

ONU (2015). Transformar nuestro mundo: La agenda 2030 para el desarrollo sostenible. A/RES/70/1 de 21 de octubre de 2015. https://www.agenda2030.gob.es/recursos/docs/APROBACION_AGENDA_203 $0 . p d f$

Pérez-Martín, J. M., \& Bravo-Torija, B. (2018) Experiencias para una Alfabetización Científica que Promueva la Justicia Ambiental en Distintos Niveles Educativos. Revista Internacional de Educación para la Justicia Social, 7(1), 119-140. https://doi.org/10.15366/riejs2018.7.1.006

Pérez-Martín, J. M., González-Patiño, J., Esquivel-Martín, T., Ambrona, T., Bravo-Torija, B., \& Atrio-Cerezo, S. (2019). Marine Litter Hub: Comunidad de aprendizaje expandida en Secundaria. En M. González Montero de Espinosa, A. Baratas Díaz, \& A. Brandi Fernández (Eds.), Experiencias didácticas en el ámbito STEM. Investigación y Didáctica en Ciencia, Tecnología, Ingeniería y Matemáticas. (pp. 183-190). Editorial Santillana.

Pérez-Rojo, P. (2013). La Educación Ambiental como tema transversal en el área de conocimiento del medio. TFG de Grado Maestro Educación Primaria de la Universidad de Valladolid. http://uvadoc.uva.es/bitstream/handle/10324/3223/TFG-B.238.pdf? sequence $=1 \&$ is Allowed $=y$

Pro, A. (2013). Enseñar procedimientos: por qué y para qué. Alambique. Didáctica de las Ciencias Experimentales, (73), 69-76.

Reigosa Isern, N., \& Pérez-Martín, J. M. (2019). Educación Ambiental y para la Sostenibilidad en Educación Infantil. Una propuesta de investigación-acción competencial. Revista de investigación Magister, (4). http://t.ly/LAg3 
Rojano, S., \& Jiménez, M. A. (2017). Propuesta didáctica de espacios ambientales en las aulas de Educación Infantil. Innoeduca. International Journal of Technology and Educational Innovation, 3(1), 66-74.

Sauvé, L. (1999). La educación ambiental entre la modernidad y la posmodernidad: En busca de un marco de referencia educativo integrador. Tópicos, 1(2), 7-27. http://www.ecominga.uqam.ca/ECOMINGA_2011/PDF/BIBLIOGRAPHIE/GUI DE_LECTURE_1/5/2.Sauve.pdf

Sauvé, L. (2004). Perspectivas curriculares para la formación de formadores en educación ambiental. Actas I Foro Nacional sobre la Incorporación de la Perspectiva Ambiental en la Formación Técnica y Profesional. Universidad Autónoma de San Luis de Potosí, México, del 9 al 13 de Junio, 2003. https://www.miteco.gob.es/en/ceneam/articulos-deopinion/2004_11sauve_tcm38-163438.pdf

Sierra, L. (2012). La educación ambiental o la educación para el desarrollo sostenible: su interpretación desde la visión sistémica y holística del concepto de medio ambiente. Educación y Futuro, (26), 17-42.

Siry, C., \& Kremer, I. (2011). Children explain the rainbow: using young children's ideas to guide science curricula. Journal of Science Education and Technology, (20), 643-655. https://www.learntechlib.org/p/167390/

UNESCO. (1975). Carta de Belgrado: un marco general para la educación ambiental. Seminario Internacional de Educación Ambiental. https://unesdoc.unesco.org/ark:/48223/pf0000027608_spa

UNESCO. (1990). Educación ambiental: modulo para la formación de profesores de ciencias y supervisores para escuelas secundarias. Oficina Regional de Educación de la Unesco para América Latina y el Caribe (OREALC). http://t.ly/eY6a

Vega Marcote, P., \& Álvarez Suárez, P. (2005). Planteamiento de un marco teórico de la Educación Ambiental para un desarrollo sostenible. Revista Electrónica de $\begin{array}{llll}\text { Enseñanza de las } & \text { Ciencias, }\end{array}$ http://reec.uvigo.es/volumenes/volumen4/ART4_Vol4_N1.pdf

Vilches, A., \& Gil Pérez, D. (2012). La educación para la sostenibilidad en la universidad. El reto de la formación del profesorado. Revista de Curriculum y Formación de Profesorado, 16(2), 25-43. http://www.ugr.es/ recfpro/rev162ART3.pdf

Vilches, A., \& Gil Pérez, D. (2015). Ciencia de la Sostenibilidad: ¿una nueva disciplina o un nuevo enfoque para todas las disciplinas? Revista Iberoamericana Educación, 69(1), 39-60. https://doi.org/10.35362/rie691152 


\section{Anexo}

Tabla suplementaria 1. Resumen de la propuesta de aula desarrollada en el trabajo.

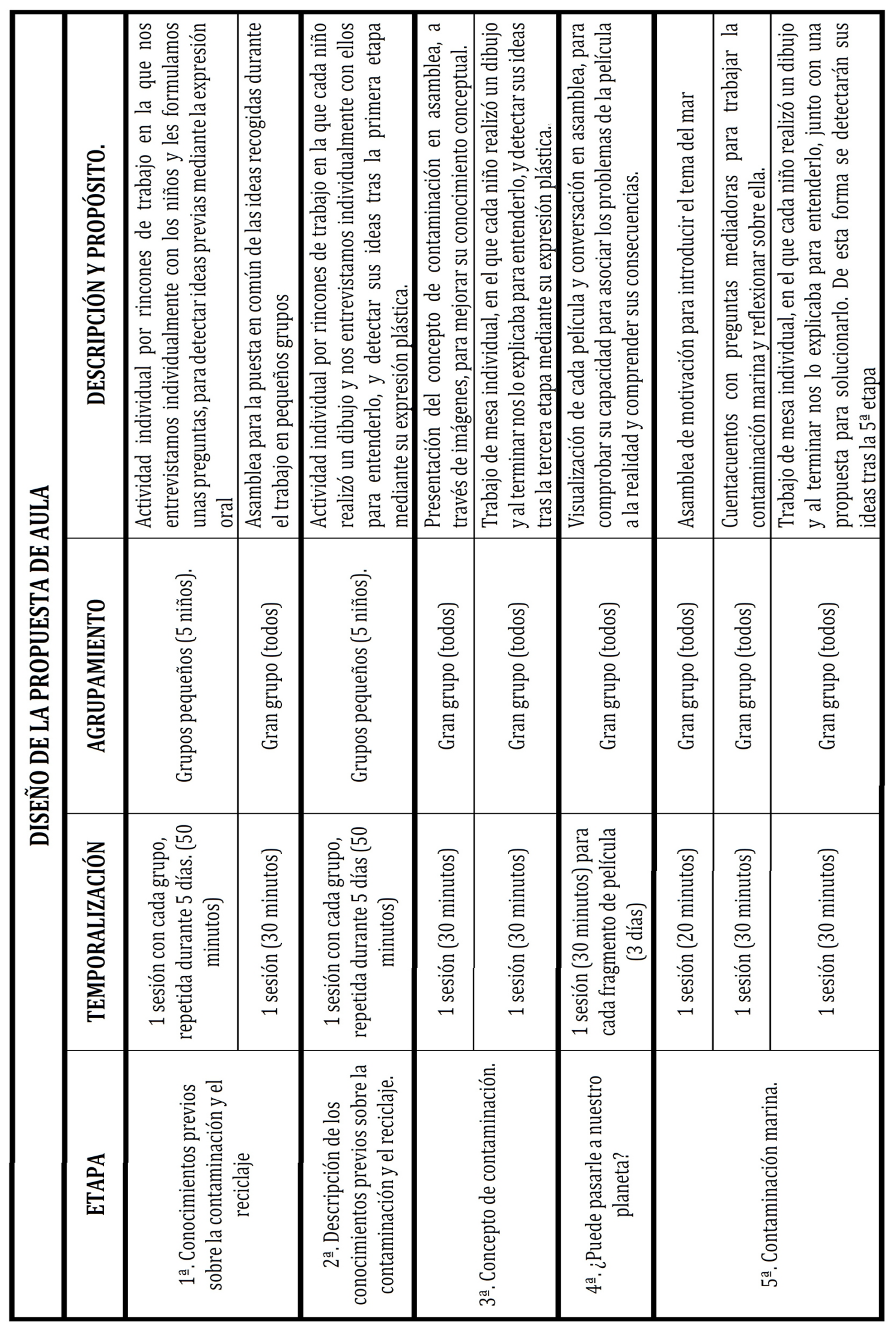

